\title{
An Exploration of New Superintendent Mentoring and Goal Setting
}

\author{
Jia “Grace" Liang, Kansas State University \\ Donna Augustine-Shaw, Kansas State University \\ James Sottile, Missouri State University
}

\begin{abstract}
Using surveys and focus group interviews, this study explored the perspectives of new school superintendents and their mentors on goal setting in relation to national leadership standards in a formal mentoring and induction program. While the two groups shared certain views, statistically significant differences were found. The mentees displayed a contextualized understanding of advocacy--more related to local community values and beliefs than those of national or international views. The issue of goal setting, or lack thereof, and the engagement of national leadership standards to mentoring are most prominent and novel in this study.
\end{abstract}

Keywords: mentoring, superintendent, leadership standards

As executive leaders, school superintendents are expected to incorporate advocacy into their leadership practices to promote equal educational opportunity and student well-being. While the work of a superintendent generally encompasses the instructional, managerial, and political domains (Bjork, BrowneFerrigno, \& Kowalski, 2014), moral stewardship is core to the superintendency (Greenfield, 2004; Maxwell, Locke, \& Scheurich, 2014). Researchers have found that superintendents increasingly spend time on mandates and reforms, experience high stress, and yet are determined to have impactful influence on student outcomes (Fale \& Ike, 2016). In the latest AASA national study of the superintendency, superintendents rated instructional leadership as one of their top three priorities (Kowalski, McCord, Petersen, Young, \& Ellerson, 2011). Given their position within the organization, superintendents hold advantages to promote and support instructional improvement and equity-oriented, high academic performance for all stu- dents. They do so through shaping goals and objectives, influencing organizational behaviors and practices, directing organizational resources, and fostering organizational culture and relationships (e.g., Fusarelli \& Fusarelli, 2005; Leithwood \& Jantzi, 2008).

The present study is part of a larger research project that explores new school and district leaders' mentoring and induction experiences in one Midwestern state of the United States. The present exploratory study focused on first-year superintendents and their goal setting. The three guiding research questions were: (1) How do first-year superintendents view their goal setting in relation to the leadership standards? (2) How do mentors view the new leader mentees' goal setting in relation to the leadership standards? (3) In what ways, if any, do the views of new superintendent mentees and their mentors differ?

\section{Literature Review: Superintendent Mentoring and Goal Setting}

Mentoring models for novice principals and superintendents began to emerge in the late 1980s and early 1990s (Alsbury \& Hackmann, 2006). Designed predominantly by university-based administrator preparation programs and state policymakers, these models were intended for "stimulating reflective practice and providing technical expertise, role clarification, and socialization in a more authentic context" (Alsbury \& Hackmann, 2006, p. 169). Despite an increasing acknowledgement of the importance of context for district-level leadership (Bjork et al., 2014), little of the scholarship in leadership and mentoring in the extant U.S. leadership development literature has centered on the superintendency in either theory or praxis (Maxwell et al., 2014; Ylimaki \& Brunner, 2014).

The limited literature on mentoring at the superintendent level has led the researchers of this study to 
draw on the extant literature on mentoring and principal induction to help frame the theory of the current study. Researchers have underscored the importance of sustained, job-embedded induction for school administrators to support them in acquiring the skills they need to succeed (Liang \& Augustine-Shaw, 2016). Mentoring of novice leaders must be relevant in the sense that it speaks to the needs and specific context of the mentee (Liang \& Augustine-Shaw, 2016; Lochmiller, 2014). Further, the focus of mentoring should be moving from product-oriented to process-oriented models that emphasize relationship building and professional reflection (Celoria \& Hemphill, 2014).

In the U.S. context, embedded in the curriculum of leadership preparation programs and individualized mentoring and induction programs are knowledge, skills, and dispositions aligned closely with the national leadership standards known as the Interstate School Leaders Licensure Consortium (ISLLC) 2008 standards (Anderson, 2009). Though the Professional Standards for Educational Leaders (PSEL) was published in November 2015, it to a great extent builds upon the solid foundation of the ISLLC standards (Murphy, Seashore Louis, \& Smylie, 2017). The states' adoption or adaptation of the ISLLC standards for use in their own state contexts and incorporation of the standards into their state professional licensure and accreditation requirements presents a reality that these educational leadership standards are not only the embodiment of such national norms but also have real implications for practitioners, leadership preparation programs, and policy makers. Given that mentoring is tied to state licensure requirements, clear reference to the national educational leadership standards can serve a dual purpose in mentoring: (a) It provides a logical progression of moving theory to practice for first-year leaders, and (b) it promotes more targeted development of leadership knowledge and skills, communicated through a common language about quality leadership and subsequently informs the beginning years of practice.

Another theoretical component relevant to the current study is goal-setting theory. The theory speaks to setting goals and performance: individuals who set specific, high (difficult) goals perform better than those who set general, easy goals (Locke \& Latham, 2013). A goal is "the object or aim of an action" or "the level of performance to be attained" in the workplace (Locke \& Latham, 2013, p. 4). The four key moderators of goal setting are feedback, commitment to the goal, task complexity, and situational constraints (Locke \& Latham, 2013). Goal setting is not alien to the leadership discipline or practice. In their review of the extensive literature related to leadership and goal setting,
Piccolo and Buengeler (2013) well elucidated why goals and goal setting have become "a central aspect of how leadership is defined in general, and effective leadership in particular" (p. 357).

Nonetheless, there is virtually no research that has attempted utilizing the interrelated three-- leadership, goal setting, and mentoring--to explore the practice of educational leadership capacity building, particularly related to superintendents. The researchers of the current study believe that well thought-out goals, together with clear standards that communicate jobperformance expectations, can aid new leaders in targeted and important first steps. Skilled mentors who are knowledgeable about the application of leadership standards in practice can serve as a critical link for new leaders in discerning their actions based on goals and expected outcomes of stakeholders. Further, one's effort and persistence in working toward a goal tend to lead to higher attainment of the goal (Locke \& Latham, 2013).

\section{Methodology}

The researchers employed a mixed method of survey questionnaires and focus group interviews. As noted above, this study is part of a larger multi-year research project exploring new school and district leaders' mentoring and induction experiences. For the purpose of this study, only the data related to goal setting for the new superintendents and their mentors were used.

\section{The New Leaders Academy}

In this Midwestern state, obtaining a full professional licensure status involves year-long participation in a state-approved mentoring and induction program. The New Leaders Academy (pseudonym) is such a program that is hosted within the college of education at a state university. Though the two major service strands (building- and district-level) operate relatively independently, core to both are quality mentors. Mentors receive in-depth training on coaching practices, and mentee-mentor matching was made while considering factors such as geographic proximity and similar experiences. Mentors observe new mentee leaders in agreed-upon performance activities and use monthly checklists provided to mentees to discuss timely reports and tasks. The academy also includes requirements like attendance at professional organization meetings and advocacy seminars, regional and statewide cohort networking, and professional learning.

\section{Participants in the Current Study}

In the 2015-16 academic year, the academy served 24 new district leaders (see Table 1). These new leaders 
were served by 14 mentors (see Table 2). The mentee district size ranged from 225 students to 7800 students. The mentors' experiences as a mentor for the academy ranged from 1 to 6 years. All mentees and mentors participated in the survey. Data from assistant superintendent and special education director positions were excluded because of the more defined nature of the roles as compared to the superintendency. As such, the final sample included 19 new superintendent mentees and 14 mentors, totaling at a sample size of 33 .

\section{Data Collection and Analysis}

Two comparable survey questionnaires were designed: one for mentors and one for mentees. Both Likert scale and open-ended questions were used in

Table 1

Mentee Participants Demographics

\begin{tabular}{|c|c|}
\hline Item & Categories \\
\hline Position & $\begin{array}{l}\text { Superintendent }=17(6 \mathrm{~F}, 11 \mathrm{M}) \\
\text { Dual appointment }{ }^{*}=2(1 \mathrm{~F}, 1 \mathrm{M}) \\
\text { Assistant superintendent }=2(2 \mathrm{M}) \\
\text { Special education director }=2(2 \mathrm{~F}) \\
\text { Assistant special education direc- } \\
\text { tor }=1(1 \mathrm{M})\end{array}$ \\
\hline Gender & $\begin{array}{l}\text { Female }=9 \\
\text { Male }=15\end{array}$ \\
\hline $\begin{array}{l}\text { Years in } \\
\text { Administration }\end{array}$ & $\begin{array}{l}\text { Below } 10 \text { years }=10 \\
10-20 \text { years }=10 \\
\text { Above } 20 \text { years }=4\end{array}$ \\
\hline $\begin{array}{l}\text { District Size } \\
\text { (Enrollment) }\end{array}$ & $\begin{array}{l}\text { Below } 500=10 \\
500-1000=9 \\
\text { Above } 1000=5\end{array}$ \\
\hline District Type & $\begin{array}{l}\text { Rural }^{* *}=23 \\
\text { Suburban }=1\end{array}$ \\
\hline Total & 24 \\
\hline
\end{tabular}

Note. $\mathrm{F}=$ Female, $\mathrm{M}=$ Male. ${ }^{*}$ Dual appointment refers to someone who is both a building principal and superintendent for the district. In rural and often small school districts, it is not rare that a building principal also serves as the superintendent for the district. **Rural: enrollment fewer than 600 ; suburban: enrollment above 600 but less than 15,000; urban: enrollment above 15,000 (State DOE). ${ }^{\text {tThis }}$ is one of the special education directors' district. the questionnaires. The questionnaires contained three sections concerning demographics, goal setting, and program qualities. As noted above, for the purpose of this study, data analyses utilized information gathered in the first two sections of the questionnaires. The utilization of the 2008 ISLLC standards in survey items and interview questions was based on two considerations: (1) the larger research started about four months before the final version of the PSEL was released, and (2) in this Midwestern state, close alignment remains between the ISLLC 2008 standards, praxis, and state programmatic policies and efforts.

The surveys were administered online via Qualtrics. The potential participants were informed that their participation was anonymous and voluntary. At the end of the survey, participants were invited to participate in the interview phase. The survey component and the invitation for the interview component were established independently in the Qualtrics system to ensure the anonymity of the survey respondents. Descriptive statistics were obtained on each item in the survey. The analysis of variance (ANOVA) procedure was conducted to examine the perceptional differences between mentees and mentors on comparable items on goal setting. Also examined were relationships between demographic factors and perceptions on goal setting. It should be noted that the statistical results need to be interpreted with caution due to the limited sample size in the current study.

Four focus group interviews (two with mentors and two with mentees) were conducted. One of the initial considerations in constructing interview protocols was to focus on the new superintendent mentees' goal setting; therefore, only the mentee interview protocol asked questions related to goal setting. As a

Table 2

Additional Mentee Participants Demographics

\begin{tabular}{ll}
\hline Item & Categories \\
\hline Career Status & $\begin{array}{l}\text { Retired superintendent }=7 \\
\text { Practicing superintendent }=6 \\
\text { Other }=1\end{array}$ \\
Gender & $\begin{array}{l}\text { Female }=5 \\
\text { Male }=9\end{array}$ \\
Years as & Below 2 years $=9$ \\
Academy & $2-4$ years $=1$ \\
Mentor & Above 4 years $=4$ \\
& \\
Total & 14
\end{tabular}


result, only the mentee interview data were included for analysis. All interviews were audio-recorded and later transcribed. The interviews provided an opportunity for more in-depth exploration on the targeted aspects examined in the survey. In particular, the interviews allowed the researchers to ask questions related to emerging patterns observed in the survey results. The interview questions in the mentee interview protocol related to goal setting were: (a) Of the six leadership standards, what have been the top two in your goal setting for the first year? Why? (b) How would you define management in your role as a superintendent/assistant superintendent? In your opinion, what tasks are managerial? (c) How would you define advocacy? What tasks in your role as a superintendent/assistant superintendent are enactments of advocacy?

In the end, four mentees (of the initial seven who agreed to be interviewed) participated. The four superintendent mentees interviewed generally reflected the overall mentee survey sample (see Table 1). The interviewee group consisted of two males and two females; two had less than 10 years of experience in administration and the other two had 10-20 years. Per the district categories noted in Table 1, three of the four participants worked in rural districts and the remaining one worked in a suburban district.

Content analysis (Neuendorf, 2002) was applied to the interview data. The analytical process was inductive primarily and deductive to a lesser degree. It was primarily inductive because the focus group interview transcripts were read repeatedly as the patterns began to emerge. It was also deductive to a lesser degree in the sense that the researchers were informed by the literature of leadership standards and mentoring as they approached the data analysis. The researchers conducted coding independently on the data first and then reviewed for coding consistency. Discrepancies were resolved through reassessment on the codes and consensus building between the researchers. Categorization of codes and generation of themes followed the similar reviewand-agreement process (Denzin \& Lincoln, 2010). The same process to review differences and reach consensus was applied to constructing categories from the agreed-upon codes, combining and refining categories, and identifying and finalizing the emergent themes. The triangulations by researcher, data source, and method (Patton, 2001) were instrumental for strengthening the trustworthiness of the findings.

\section{Results and Discussion}

Overall, the survey data, to a great extent, suggested an agreement between the superintendent mentees and the mentors on establishing goals in relation to the six leadership standards. Nonetheless, statistically significant disparities were revealed on certain standards between the two groups. Further, three themes emerged from the mentee interview data, providing more contextualized insights on the survey results.

\section{Survey Results}

In the first subsection, both mentees and mentors were asked to rate the importance of each of the six educational leadership standards to the goals set by the mentee for the first year on the job (see Table 3). All ratings were above 4 (on a 5-point scale from "very low" to "very high"). Standard 5 (S5), Professional Ethics was rated the highest by mentees, whereas Standard 3 (S3), Management was rated the highest by mentors. In terms of the rankings across the standards, both groups rated Standard 1 (S1), Vision and Standard 6 (S6), Advocacy as the lowest in its importance for the mentee's first-year goals. The ANOVA results confirmed the perceptional disparity on S3, Management between the mentee and mentor groups, $F(1,31)=$ $4.239, p<.05$.

The observations seemed to suggest that both mentees and mentors focused on the aspects of leadership that require mostly individual effort, such as professional ethics and management in the first-year goal setting. One could view this as the task complexity moderating goal setting (Locke \& Latham, 2013). This is not to say that to perform leadership in these domains does not involve working with others. Nevertheless, in relation to other standards such as advocacy and vision, often regarded as the most challenging aspects of leadership and highly collective in nature as noted in the literature (Tucker, Anderson, Reynolds, \& Mawhinney, 2016), the professional ethics and management standards could be considered as containing competency components that for which one can be more confident in expecting growth with increased individual knowledge and skills.

The mentees' rating of S1 Vision as the lowest also seemed to echo the reservation and/or caution of the new leaders noted in the literature, as they had yet to establish sufficient knowledge of the local values, norms, traditions and expectations and to garner necessary sociocultural and human capital to tackle the tasks of developing, articulating, and implementing a collective vision of learning (Kamrath \& Brunner, 2014). Both mentees and mentors rated S3 Management high for first-year goal setting, suggesting a shared knowledge that management is inseparable from leadership, especially when leading a school system. The significantly higher average rating the mentors had (than mentees') on S3 Management could be a result of 
Table 3

Importance Ratings of the Standards for First-Year Goals on the Job

\begin{tabular}{lcccc}
\hline & \multicolumn{2}{c}{ Mentee $(\boldsymbol{n}=\mathbf{1 9})$} & \multicolumn{2}{c}{ Mentor $(\boldsymbol{n}=\mathbf{1 4})$} \\
\cline { 2 - 5 } Item & $\boldsymbol{M}$ & $\boldsymbol{S D}$ & $\boldsymbol{M}$ & $\boldsymbol{S D}$ \\
\hline Shared School Vision of Learning & 4.26 & 0.56 & 4.21 & 0.70 \\
School Learning Culture & 4.47 & 0.51 & 4.21 & 0.70 \\
Management* & 4.53 & 0.51 & 4.86 & 0.36 \\
Collaboration & 4.42 & 0.70 & 4.36 & 0.75 \\
Professional Ethics & 4.68 & 0.58 & 4.57 & 0.65 \\
Advocacy & 4.42 & 0.69 & 4.14 & 0.77 \\
\hline
\end{tabular}

a much keener awareness and understanding of the often business-dominated nature of school board (Bjork et al., 2014) and its potentially negative influence on the superintendent-board relationship, as well as the severe consequences that an "unsatisfactory" performance in management could lead to for a new leader.

In the second subsection, the statement items remained the same; however, this time the mentees and mentors were asked about how they perceived the importance of the standards in the mentees' goals for the future (see Table 4). S5 Professional Ethics remained the highest-rated by the mentees, followed by $S 6 \mathrm{Ad}$ vocacy and S3 Management. The mentors also rated S5 Professional Ethics highest, followed by S3 Management and S4 Collaboration. S1 Vision remained ranked the lowest by both mentees and mentors. Furthermore, $S 6$ Advocacy, though it had increased ratings on mentees' responses, was still rated the lowest (as was S1 Vision, but with a smaller standard deviation) by mentors. ANOVA results revealed that the perceptional disparity between mentees and mentors on S6 Advocacy was significant, $(F(1,30)=9.630, p<.01)$ as well as the perceptional difference between the two groups on $S 5$ Professional Ethics $(F(1,31)=5.568, p<.05)$. Further, there were similar mentor mean ratings on S5 Professional Ethics $\left(\bar{x}^{-}=4.64\right)$, S3 Management $\left(\bar{x}^{-}=4.57\right)$, and S4 Collaboration $\left(x^{-}=4.57\right)$, suggesting the mentors did not necessarily think that setting S5-related goals was drastically more important than other goals in other standard domains. In contrast, the mentee mean rating on S5 was almost at the highest rating of " 5 " with a noticeably small standard deviation of .23. This could be related to the realization that the new superintendent mentees had concerning the criticality of self-awareness, professionalism, and integrity for sitting in the superintendency (McClellan, Ivory, \& Dominguez, 2008).

As for the result that both mentees and mentors rated S1 Vision the lowest for future goals, a possible explanation could be that both groups understood that a good vision is robust and sustainable. Given the national average tenure for a superintendent is somewhere between three to four years (Chingos, Whitehurst, \& Lindquist, 2014), it would be reasonable to expect that efforts related to S1 Vision tend to occur early in one's superintendency. It was a surprise to the researchers that the mentors rated S6 Advocacy statistically significantly lower than the mentees did on its importance for setting future goals. It is possible that the mentors, while experienced, were trained and began their educational administrative career in a different time from their mentees; therefore, their indoctrination to the term "advocacy" and its critical ideological connotation may be limited. In contrast, the mentees, being much younger, could have been immersed with such framing in both of their preparation and professional administrative roles.

The third subsection asked about the mentee's current performance on the standards (Table 5). The mentees rated S5 Professional Ethics the highest, followed by S6 Advocacy. The mentors also rated S5 Professional Ethics the highest, but followed by S3 Management. The mentees rated S3 Management the lowest, while the mentors rated S6 Advocacy the lowest. Also, when the means of the ratings on each of the standards were examined, the mentors tended to rate the mentees slightly higher than the mentees rated themselves, except for S5 Professional Ethics. ANOVA results reveal a statistically significant difference between the ratings by the two groups on S3 Management $(F(1,31)=4.787, p<.05)$. The results seemed to suggest that mentors, with extensive superintendent experience, had more realistic expectations on the levels of growth their mentees could have within a year. The much lower ratings that the mentees gave to themselves (all below 3.9 except for S6 Advocacy at 3.95 and S5 Professional Ethics at 4.68 versus the mentors' ratings of all above 4.1 except for S6 Advocacy at 4.07 ) could be the result of the pressure felt due to needing to learn many things concurrently and running the district at the same time. As for the 
Table 4

Importance Ratings of the Standards for Future Goals

\begin{tabular}{lcccc}
\hline \multirow{2}{*}{ Item } & \multicolumn{2}{c}{ Mentee } & \multicolumn{2}{c}{ Mentor } \\
\cline { 2 - 5 } & $\boldsymbol{M}$ & $\boldsymbol{S D}$ & $\boldsymbol{M}$ & $\mathrm{SD}$ \\
\hline Shared School Vision of Learning & 4.58 & 0.51 & 4.29 & 0.73 \\
School Learning Culture & 4.68 & 0.48 & 4.36 & 0.75 \\
Management & 4.74 & 0.45 & 4.57 & 0.65 \\
Collaboration & 4.68 & 0.49 & 4.57 & 0.65 \\
Professional Ethics* & 4.95 & 0.23 & 4.64 & 0.50 \\
Advocacy $^{* *}+$ & 4.83 & 0.38 & 4.29 & 0.61 \\
\hline
\end{tabular}

Note. ${ }^{*} p<.05 .{ }^{* *} p<.01 .{ }^{\dagger} \mathrm{A}$ missing data point in the mentee group, $n=18$.

Table 5

Ratings of the Mentee Performance/Progress on the Standards

\begin{tabular}{lcccc}
\hline & \multicolumn{2}{c}{ Mentee } & \multicolumn{2}{c}{ Mentor } \\
\cline { 2 - 5 } Item & $\boldsymbol{M}$ & SD & $\boldsymbol{M}$ & SD \\
\hline Shared School Vision of Learning & 3.89 & 0.66 & 4.29 & 0.61 \\
School Learning Culture & 3.89 & 0.81 & 4.14 & 0.54 \\
Management* & 3.84 & 0.83 & 4.43 & 0.65 \\
Collaboration & 3.89 & 0.81 & 4.14 & 0.54 \\
Professional Ethics & 4.68 & 0.48 & 4.50 & 0.65 \\
Advocacy & 3.95 & 0.62 & 4.07 & 0.62 \\
\hline
\end{tabular}

Note. ${ }^{*} p<.05$.

significant disparity between the mentors and mentees on S3 Management, a possible explanation could be that while the mentees could be overwhelmed by the sheer amount of work involved in one's role as a superintendent, the mentors knew that the managerial aspects tend to have standard policies and procedures and have clear answers.

ANOVA results did not reveal any statistically significant differences between the ratings by the two groups on the last subsection regarding the academy's effectiveness in facilitating standards-based goal setting (Table 6). Both groups tended to have mean ratings that ranged from 3.9 to 4.3. Further, correlation analyses on the mentee demographic factors and the goal setting ratings revealed that the position type (in a dual appointment or not) was negatively and significantly related to the first-year goal setting in relation to S4 Collaboration and S6 Advocacy, the current performance on S4 Collaboration and S5 Professional Ethics, and perceived effect of the academy's assistance on goal setting in relation to S2 Culture. The prior administrative experience was found to be positively and significantly related to the first-year goal setting in relation to S6 Advocacy. District size was positively and significantly related to the mentee's current performance on S5 Professional Ethics. This seemed to confirm the literature on larger school districts where in- terest groups trying to influence the superintendents and school boards are more prevalent (Douglas \& Walker, 2013); therefore, one's integrity and sense of ethics are constantly under check. Lastly, gender was found to be negatively and significantly related to the participants' (mentors and mentees) rankings on future goal setting in relation to S1 Vision, mentee's performance on S6 Advocacy, and the academy's help on S6 Advocacy. That is, women participants tended to rank these variables higher than men. The findings seemed to support a general trend observed in the field concerning women and educational leadership; that is, women tend to lead more collaboratively, value relationship in leading, and arrive at the superintendency through a career trajectory consisting primarily of instructional positions (Bjork et al., 2014).

\section{Emergent Themes from Mentee Interviews}

Three themes emerged from the mentees' focus group interview data. The themes speak to the new executive leaders' commitment to student learning, the contextualized discretion they have in goal setting, and a propensity of viewing advocacy as a stewardship for place.

Commitment to student learning. The ways that the new executive leaders spoke about setting their 
goals clearly showed a commitment to student learning, echoing the literature emphasizing the instructional leadership role expectation of the superintendent (Kowalski et al., 2011). From building a shared vision, creating "a culture of continual learning," and being "intentional in collaboration," all were driven by a focus on quality instruction and student learning. At first look, the prevalence of vision noted in the interview data seemed to be contradictory to the survey results in which S1 Vision received consistent lower ratings by superintendent mentees. But a further examination into the ways that mentees brought up vision in their interviews revealed a much broader notion of the concept that was more aligned with an ultimate commitment to quality education for all students, which hardly needs to be established as one assumes of a superintendency (or any other educational roles). In contrast, S1 Vision includes a leader's ability to establish and articulate a shared vision statement. In other words, that one requires a contextualized relevancy that attends to the needs and characteristics of the district one is leading. As noted above, for a new leader who is yet to develop adequate understanding of the localities, such a task is not a small or quick one. The researchers of this study suspected that this could contribute to the apparent disparity between survey and interview data related to vision. Furthermore, it is also possible that the mentees regarded that grand vision a core principle of profes- sional ethics, which could explain the consistent high ratings of S5 Professional Ethics in the survey data.

Like superintendents in other studies (Bjork et al., 2014; McClellan et al., 2008), the new superintendents in this study recognized the importance of establishing effective communication channels and structures that involve stakeholders to increase knowledge of and promote sustained commitment to the vision. For instance, Mentee A noted, "Every time I share an update I'm sending along the vision statement, I probably got some eye-rolling and gagging there because it gets old. But you can't do enough with communicating the why and the where; the consistency." For the new district administrators, vision, culture, and collaboration tended to be directly related to quality teaching and learning in schools. They emphasized the importance of having a "truly collaborative process" to achieve a meaningful, shared vision and healthy culture. Furthermore, the ways these new leaders approached building momentum and promoting buy-in showed their attentiveness to the existing district culture. All these were consistent with the survey results in which mentees rated S2 Culture and S4 Collaboration high.

Nonetheless, when asked about how they understood management, some mentees struggled while others were able to offer well-articulated perspectives. For instance, Mentee B noted,

Table 6

Correlation Between Demographic Factors and Standards-Based Goal Setting Rankings

\begin{tabular}{lllll}
\hline Variable & $\begin{array}{l}\text { District Position } \\
(n=19)\end{array}$ & $\begin{array}{l}\text { Years in Adm. } \\
(n=19)\end{array}$ & $\begin{array}{l}\text { District Size } \\
(\text { enrollment }) \\
(n=19)\end{array}$ & $\begin{array}{l}\text { Gendera }_{(n=33)} \\
\text { Y1 S4 }\end{array}$ \\
Y1 S6 & $-.593^{* *}$ & $.589^{* *}$ & \\
FT S1 & $-.593^{* *}$ & & $-.485^{* *}$ \\
Y1P S4 & $-.530^{*}$ & & \\
Y1P S5 & $-.505^{*}$ & & \\
Y1P S6 & & & $-.356^{*}$ \\
NLA S2 & $-.471^{*}$ & & \\
NLA S6 & & & $-.358^{*}$ \\
\hline
\end{tabular}

Note. ${ }^{*} p<.05 .{ }^{* *} p<.01 . \mathrm{Y} 1=$ Year 1 goal setting. FT $=$ Future goal setting. $\mathrm{Y} 1 \mathrm{P}=$ Year 1 performance on the standard. NLA $=$ New Leaders Academy assistance on goal setting in relation to the standard. Only the significant correlations were included. aIncludes mentors and mentees. 
I don't know...what it means: good management. Things come at you so quickly; you can be, one day, walking down the hallway, 'hey, we need a new laptop for a teacher' to 'the toilet is clogged up in another building' to 'I don't know how to teach this to kindergarteners'.

This mentee previously worked in a much larger school district before taking her current position in a small rural district. Management positions in her prior school district were more structurally divided with more articulated job descriptions and a hierarchical chain of command. Because of this, she struggled with translating her previous experience and notion of management into her current position, which had a much more flattened central office structure.

In contrast, Mentee $\mathrm{C}$ responded, "I define it as an organizational understanding, ... you make everything run smoothly. ... Management things to me are sometimes cut and dry. Yes, they are coming at you all the time, but they have an easier answer." This particular mentee served as a special education director, which entailed a considerable amount of managerial responsibilities before being hired into her current district. The variation in the superintendent mentees' responses seemed to support the idea that prior professional experiences, together with the particularity of the local context, are key forces in shaping these new district leaders' goal setting, which is the second theme. Also, the interview responses on the topic of management echoed the survey results; that is, the mentees recognized that while management is not leadership, it is indispensable to effective leadership and a successful superintendency. For those whose prior administrative positions involved responsibilities that were smaller in scale, more finite in scope, and/or less politically charged, the first year in the superintendency could intensify one's sense of a capacity gap on management. This concept was supported by both the interview data and the mentees' low ratings on S3 Management in the survey when asked about their current performance.

Contextualized discretion in goal setting. The interview data suggested that the new leaders' goal setting was, more often than not, a product contextualized and negotiated based on the individual mentees' ability to shape the power dynamics among themselves, the community, and the school board. For example, Mentee B thought she would "come in [the superintendency] and focus on instruction and culture," but she "ended up with having to do a lot more management," which "ended up being [her] primary focus for the first year."

The mentees' ability to navigate, negotiate, and balance demands was dependent on his or her acquired professional knowledge, skills, and dispositions; extent of exposure to certain leadership functions or tasks; and level of self-awareness and understanding of sociocultural and political terrains of the local community. For example, Mentee D commented,

You constantly learn the culture and values of your community; the more people you talk to, the more you understand the subtleties that might be underneath the surface. You really have to adapt because if you are not very intentional about which trajectory you are going and you are not very explicit about stating what that is, that underlying culture will be more than happy to lead if you are not.

For the mentees, understanding their own strengths and articulating these in their goal-setting conversations and priorities with their mentors helped to "open up opportunities for more personalized support" based on a more holistic "mapping out" of personal and situational contributing factors. The findings echo the literature on effective mentoring, as new leaders received assistance to develop confidence in interacting with various stakeholders and dealing with multi-faceted issues (Alsbury \& Hackmann, 2006). The findings also support goal setting theory in mentoring, as new leader mentees were helped to develop specific goals to enhance selfawareness, which can lead to increased self-efficacy (Locke \& Latham, 2013). Such variations captured by interview data complemented the survey results, as they brought more nuanced information related to the phenomenon of individual backgrounds interacting with district and community contexts and shaping one's mentoring needs (as articulated in goal setting).

Advocacy as stewardship for place. The third theme was about advocacy. Advocacy for the mentees meant that they were " $24 / 7$ advocate[s]" for the benefits of their local community on state and national platforms. Essential to this advocacy was information along with understanding the values and needs of the community they represented. The mentees recognized the importance of strategic involvement in community groups to build networks, alliances, and visibility (Kamrath, 2015). Such views were exemplified by Mentee C's responses:

I define it as speaking for your learning community. You have to really know each of your participants in your community, whether it is your board - what they need and want, what your students need, or what your teachers need, and 
being able to speak to the community about that and being able to speak to your legislators about that.

When advocacy is understood as a stewardship of place, then it makes sense that the intimate understanding of the local community and its constituents has to come first before that stewardship can be materialized. This helped explain the seemingly "delay" or "low priority" on S6 Advocacy shown in the survey results. Rather than an indication of the mentees' reluctance in taking on advocacy, the interview data supplied a more contextualize interpretation of the survey results on advocacy.

\section{Implications and Conclusions}

In this exploratory study, the researchers sought to discover the leadership competency areas, as described by the standards, that the new-leader mentees regarded as priorities or needs and how/why so. The purpose of this goal was to enable the program and the mentors that participated in the program to better support the mentees. This goal and purpose was aligned with the overarching purpose of a larger research project exploring new school and district leaders' mentoring and induction experiences. This study attended to the perceptional and definitional differences between mentees and mentors on the standards. The researchers of the study recognize and argue that leadership standards can be used as a tool in mentoring and induction to open up dialogue, reveal presumptions, and promote individual and collective reflections a mentee and a mentor can have with themselves and with each other.

As revealed in quantitative and qualitative data, the emerging differences between mentees' perceptions highlighted the variance in knowledge, skills, and the attitudes of mentees as well as their past experiences. Mentees also varied in their understandings of the standards' primary functions as they applied the standards to their awareness and interpretation of the local school and community context. Mentors can play an essential role in bridging local and national conception and discourse around leadership standards, helping mentees to forge a more contextualized enactment of standards in practice. Mentors' capacity to do so is a reflection of a formal mentoring/ induction program in its ability to promote a transferable understanding of the professional standards grounded in the new leaders' personal and professional circumstances.

How do mentors assist mentees in establishing priorities aligned with their individual professional goals and the goals set by the district and board of education? How do mentors orient new leaders to the leadership standards interpreted nationally and locally and strike a healthy balance in their applications in practice? Further research is needed to capture the perceptions and (inter)actions of mentors as they work to support mentees in these areas. Implications for further research also include explorations that take into consideration the effects of the mentors' background and training in mentorship on the perceptional differences between mentors and mentees in attaining outcomes driven by goal setting aligned to leadership standards. This would include investigating stages of goal setting and leadership standards for mentees' during the first year on-the-job, in the future, and through the support of the mentoring program itself. The current study involved participants in one mentoring and induction program in a Midwestern state; future studies need to be conducted in different geographic locations, under different program structures, or with participants who hold different characteristics from those in the current study to see if the current findings still hold applicable.

The findings of the study seemed to indicate that mentors predominately focused on first-year survival skills of new superintendents as they sought to lead and improve their local schools. Mentors are thrust into situations that require a delicate attending to the pressing issues that occurred in the mentees' immediate environments and deeper leadership conversations inclusive of advocating for local community needs in the state and national forum. The findings also confirm the criticality of the boardsuperintendent relationship to superintendent success. The initial relationship between the superintendent and the local board of education often determines whether the board chooses to buffer or mediate conflicting cultural and political demands of the larger context with the values and traditions of the local community. Further research is needed to understand the dynamics of mentoring support in this regard as well.

The perceptional disparities between mentors and mentees revealed in the findings also have implications for mentoring and induction programming. While professional experience, along with some coaching techniques or strategies, matters when it comes to a mentor's ability to mentor a novice-leader mentee, it is equally important, if not more, to genuinely consider a candidate's (as mentor or mentee) values and beliefs that he or she brings to the mentoring relationship at the program planning stage, if all possible. Relative to more readily accessible information that is commonly used for mentee-mentor matching such as district size, past position, and geographic location, values and beliefs are less directly 
observable and at times elusive to gauge beforehand for programs. Nonetheless, as Touchton, Taylor, and Acker-Hocevar (2012) argued, present and future leaders must first and foremost know what they stand for and be aware of their beliefs and values in order to practice ethical decision making. Admittedly, engaging such deep, critical reflections individually and collectively on one's self in relation to one's leadership role and community within and without can be challenging for both a mentee and a mentor, especially at the beginning of the process when trust and relationships have yet to be established. During this early acclimation period, bringing in the leadership standards to educate both parties could serve as an entry point for meaningful conversations, leading to selfawareness.

To conclude, as state and professional organizations and universities explore meaningful partnerships to plan and deliver sustainable mentoring programs, voices need to be heard from co-travelers in this mentoring journey. The current study offers insight into how one model is embedding mentor practices into local contexts through goal setting that builds capacity in superintendent leadership. In the initial years of practice, mentors can assist new leaders in maneuvering through political and demanding climates by offering reflection and expert judgement, helping mentees discern how their goals contribute to organizational expectations. When skilled and knowledgeable mentors ground discussion in leadership preparation standards that articulate performance outcomes, new leaders can prioritize goals and manage their time more effectively. Through continued examination of operating mentoring and induction programs for new superintendents, program models can be more succinctly articulated to define effective program components and requirements.

\section{References}

Alsbury, T. L., \& Hackmann, D. G. (2006). Learning from experience: Initial findings of a mentoring/ induction program for novice principals and superintendents. Planning \& Changing, 37(3/4), 169189.

Anderson, G. L. (2009). Advocacy leadership: Toward a post-reform agenda in education. New York, NY: Routledge.

Bjork, L. G., Browne-Ferrigno, T., \& Kowalski, T. J. (2014). The superintendent and educational reform in the United States of America. Leadership and Policy in Schools, 13(4), 444-465.
Celoria, D., \& Hemphill, D. (2014). Coaching from the coaches' perspective: A process-oriented focus. International Journal of Mentoring and Coaching in Education, 3(1), 72-85.

Chingos, M. M., Whitehurst, G. J., \& Lindquist, K. M. (2014). School superintendents: Vital or irrelevant? Washington, DC: Brown Center on Education Policy, The Brookings Institute.

Denzin, N. K., \& Lincoln, Y. S. (2010). Introduction: The discipline and practice of qualitative research. In N. K. Denzin \& Y. S. Lincoln (Eds.), The Sage handbook of qualitative research (4th ed., pp. 1-20). Thousand Oaks, CA: Sage.

Douglas, S., \& Walker, A. (2013). Coal mining and the resource curse in the eastern United States. Morgantown, WV: Social Sciences Research Network.

Fale, E., \& Ike, R. (2016). The 9th triennial study of the superintendency in New York. Albany, NY: The Council of School Superintendents.

Fusarelli, B. C., \& Fusarelli, L. (2005). Reconceptualizing the superintendency: Superintendents as applied social scientists and social activists. In L. Bjork, L. \& T. Kowalski (Eds.), The contemporary superintendent: Preparation, practice and development (pp. 187-206). Thousand Oaks, CA: Corwin.

Greenfield, W. D. (2004). Moral leadership in schools. Journal of Educational Administration, 42(2), 174-196.

Kamrath, B. (2015). Power disconnections: A multiple case study of staff members and superintendents in small rural school districts with high superintendent turnover. Journal of Ethnographic \& Qualitative Research, 10(2), 104-119.

Kamrath, B., \& Brunner, C.C. (2014). Blind spots: Small rural communities and high turnover in the superintendency. Journal of School Leadership, 24(3), 424-451.

Kowalski, T. J., McCord, R. S., Petersen, G. J., Young, I. P., \& Ellerson, N. M. (2011). The American school superintendent: 2010 decennial study. Lanham, MD: Rowan \& Littlefield Education.

Leithwood, K., \& Jantzi, D. (2008). Linking leadership to student learning: The contribution of leader efficacy. Educational Administration Quarterly, 44 (4), 496-528.

Liang, J. G., \& Augustine-Shaw, D. (2016). Mentoring and induction for new assistant principals. International Journal of Mentoring and Coaching in Education, 5(3), 221-238.

Lochmiller, C. R. (2014). Leadership coaching in an induction program for novice principals: A 3-year study. Journal of Research on Leadership Education, 9 (1), 59-84. 
Locke, E. A., \& Latham, G. P. (Eds.). (2013). New developments in goal setting and task performance. New York, NY: Routledge.

Maxwell, G. M., Locke, L. A., \& Scheurich, J. J. (2014). The rural social justice leader: An exploratory profile in resilience. Journal of School Leadership, 24(3), 482-508.

McClellan, R., Ivory, G., \& Dominguez, R. (2008). Distribution of influence, communication, and relational mentoring in the US superintendency. Mentoring $\mathcal{E}$ Tutoring: Partnership in Learning, 16(3), 346-358.

Murphy, J., Seashore Louis, K., \& Smylie, M. (2017). Positive school leadership: How the professional standards for educational leaders can be brought to life. Kappan, 99(1), 21-24.

Neuendorf, K. A. (2002). The content analysis guidebook. Thousand Oaks, CA: Sage.

Patton, M. Q. (2001). Qualitative evaluation and research methods (2nd ed.). Thousand Oaks, CA: Sage.

Piccolo, R. F., \& Buengeler, C. (2013). Leadership and goal setting. In E. A. Locke \& G. P. Latham (Eds.), New developments in goal setting and task performance (pp. 357-374). New York, NY: Routledge.

Touchton, D. J., Taylor, R. T., \& Acker-Hocevar, M. A. (2012). Decision-making process, giving voice, listening, and involvement. In M. A. AckerHocevar, J. Ballenger, A. W. Place, \& G. Ivory (Eds.), Snapshots of school leadership in the 21st century (pp. 121-146). Charlotte, NC: Information Age Publishing, Inc.

Tucker, P. D., Anderson, E., Reynolds, A. L., \& Mawhinney, H. (2016). Analysis of evidence supporting the Educational Leadership Constituent Council 2011 Educational Leadership Program Standards. Journal of Research on Leadership Preparation, 11(1), 91-119.

Ylimaki, R. M., \& Brunner, C. C. (2014). Introduction: The rural superintendency. Journal of School Leadership, 24(3), 418-423.

\section{Authors}

Jia "Grace" Liang, PhD, holds a doctorate in educational administration and policy from the University of Georgia. She is currently an assistant professor in the Department of Educational Leadership at Kansas State University, 1114 Mid-Campus Drive N., Manhattan, KS 66506. She may be contacted at gliang15@ksu.edu or 785-532-5535. Her research interests focus on school leadership, capacity building in teaching and leading, equity for women and racial minorities, and leadership for community engagement.
Donna Augustine-Shaw, EdD, holds a doctorate in educational administration from Wichita State University and is an associate professor in the Department of Educational Leadership at Kansas State University. She may be contacted at donna5@ksu.edu. Her areas of research are the superintendency and mentoring.

James Sottile, $\mathrm{PhD}$, holds a doctoral degree in educational psychology from West Virginia University and is a Professor in the College of Education at Missouri State University, Springfield, MO 65897. He may be contacted at James.Sottile@MissouriState.edu. His research interests are related to equity and diversity in education, student development, teacher professional development in math and science, academic integrity, and program assessment and evaluation. 